Covered in: ERIH PLUS, CEEOL, Index Copernicus, CrossRef, CrossCheck, J-Gate, Google Scholar, Ideas RePeC, Econpapers, Socionet, KVK, WorldCat.

\section{Aspects of Technology in Contemporary Art Education}

\section{Mihai-Ionuț RUSEN1}

${ }^{1}$ PhD, Lecturer, National University of Arts, Bucharest, Romania, mihai rusen@yahoo.com

\begin{abstract}
Technology might just be a contemporary solution to the ever-growing gap between younger student generations and the teaching systems in Art Education, which has led to lowest levels ever of attending students in modern artistic education in Romania. In our opinion, a potential solution is to approach artistic transposition technologies from two perspectives: first, implementing existing digital technologies, and adapting them to a competitive Art Education system correlated with realities in the labor market - 3D scanning and printing, augmented reality, graphic and concept design on digital support, unconventional materials, online and social media documentation, smart-phone creative applications, constant involvement in creative and participatory projects, artistic research and experimentation. The second perspective involves traditional technologies, or creatively identified as expired technologies - those of the industrial age of the last century. Those are part of the history and already developed aesthetic and cultural potential, at least for the Visual Arts - e.g. Typewriter Art. We may consider as object of study for Visual Arts a whole post-industrial archive - blueprints, designs, and accessible artifacts of the age. Through Artistic Research methods we are able to facilitate the practice of contemporary art technologies and democratize access to creativity, originality and experimental knowledge in a highly professional field, deeply dependent on abilities and skills whose traditional development is today prohibitive expensive - resources, time and a global labor market with requirements already adapted to contemporary creative realities.
\end{abstract}

Keywords: technology; contemporary art; artistic research; art education; education system; post-industrial archive.

How to cite: Rusen, M.-I. (2018). Aspects of Technology in Contemporary Art Education. Logos Universality Mentality Education Novelty: Philosophy \& Humanistic Sciences, 6(2), 18-36. https://doi.org/10.18662/lumenphs/08 



\section{The Artistic Research in the context of contemporary art education.}

Artistic research is still a novelty in contemporary art universities. The ultimate goal is to close the gap between science and art and to create a functional scientific paradigm across modern university research. It looks and sounds maybe utopian, but we take into account the premise that technology (before digital and cutting edge modern) could slowly narrow this gap by applying, developing and mixing various emerging technologies in the context of contemporary Visual Arts and culture. The artistic research is by definition multi-disciplinary, practicing cross sections and shifting perception over the cultural phenomenon, forming a contemporary university discipline whose modus operandi is practice-based and practice driven over area of contemporary culture.

Even natural scientific research alone is very diverse in its objects, methods and products, as McAllister (2004) notes. How much more this applies to research including the bumanities and social sciences, and further industrial, market or opinion research. Not surprisingly, this is also true for artistic research. Among the authors cited here, there is agreement that this diversity has to be preserved against efforts to canonical restrictions. (...) Art without research is lacking an essential foundation, as this is the case for science. As cultural developments, both live on the balance between tradition and innovation. Tradition without research would be blind takeover, and innovation without research would be pure intuition. Wherever scientists do not research but teach, judge, advise, treat, apply, or talk more or less telegenically (hence: "PUSH"... the button), they might still operate science - but if they undertook this all without research, they were not quite in their cause. The same can be said of artists. On the other hand it is clear that not all art quite counts as research, as little as this is the case for science (Klein, 2010).

According to the UNESCO definition, research is "any creative systematic activity undertaken in order to increase the stock of knowledge, including knowledge about bumanity, culture and society, and the use of this knowledge to devise new applications." (OECD, 2008).

Artistic research is more than welcome in the process of art education, due to its methods superposition on university teaching and learning: searching, archiving, collecting, interpreting and explaining, modeling, experimenting. Research and critical thinking are the main ingredients to gradually fracture the protochronism of a tradition defined today by form without substance. It also motivates teaching staff, usually artists themselves, to stay connected to realities and trends of contemporary Visual Arts - each generation of students brings new challanges, ideas and 
concepts imposed by contemporary culture. There is even a project fully dedicated to Artistic Research: The Journal for Artistic Research (JAR) is an international, online, Open Access and peer-reviewed journal for the identification, publication and dissemination of artistic research and its methodologies, from all arts disciplines. With the aim of displaying practice in a manner that respects artists' modes of presentation, JAR abandons the traditional journal article format and offers its contributors a dynamic online canvas where text can be woven together with image, audio and video. These research documents called 'expositions' provide a unique reading experience while fulfilling the expectations of scholarly dissemination (SAR, n.d.).

\section{Methods of Artistic Research in contemporary Visual Arts.}

Any notable work of art is well established by the taxonomy of Art History, including the contemporary Visual Arts. And yet, most important for the methods of artistic research is the story behind the object, the artist and the context; in fact, the process of the work of art is the drive and usually produce a body of material that stand as keystone to future evolution and research. This body of material consists of sketches, objects, documentation, drawings, photographs, videos, audiotapes, texts, research diaries and so on; all in all it becomes a public record of the phenomena available to anyone performing a research on the topics. Behind the work of art, the ideas, concepts and context, there is always the technology of object in the making - traditionally analogue, postmodern or cutting edge digital and contemporary; as insiders and knowing the result, the technology of transposition, the artist's background and the founding concepts, we are able to investigate, research, formulate and propose alternative visions, explanations and perceptions aver the subjects investigated. Direct methods of artistic research are based on documentation over internet and books/art albums, about the works/objects of art, artists, concepts and context; method is considered the supporter and stimulator of the researcher's intuitive ideas: case studies, media analysis, practice-based \& practice-led research, art practice as research, creative research.

This study aims to explain how artistic transposition technologies originating from traditional, postmodern and contemporary technology applications could become the main drive for the evolution of art education at the beginning of this century.

Most of case studies and art works presented relate mainly to the sculptural potential of artefacts, investigated through artistic research methods. The typology of artifacts mentioned or analyzed in here has as a common denominator the diversity of the technological processes through 
which these have been made - from traditional, postmodern or contemporary technologies; the artefacts are also diverse, starting from the digital applications up to the timeless anthropological technologies of ritual and imitative magic for vodoo artefacts. This article has documented the most recently published books and art albums - monographies, interdisciplinary and cross section projects, art criticism - internet and media analysis, and finally the extended personal experience in visual arts and art education: practice-based \& practice-led artistic research.

\section{The Typewriter Art.}

In contemporary artistic education, the typewriter art is the ideal example for the values of a traditional technology (once high-tech, cutting edge technology), now completely overcome, but with a great potential for contemporary art, including artistic experimentation. Fascinating however, is the former ideological status of this artifact, especially behind the Iron Curtain - that is why the typewriter art is also a symbol for freedom of expression, in extreme ideological context. And these are the facts: although necessary for any developing country, the typewriter was considered an unsafe ideological object, due to its ability to spread personal ideas, outside of state control, dangerous as a weapon, so all its characters, mainly the letters and every other signs are considered fingerprints, identifiable by forensic type analysis. So during the communist era, the typewriter had to be registered with the Police/People's Militia, with a firearm-like registration procedure, which included a document page typed with all the characters of the machine that had to be kept for any possible investigation or identification process, like a forensic ballistic test.

The typewriter had a modern artistic potential from the beginning. In 1900, was already published a manual/handbook for the Typewriter Art obviously promoted as a commercial and marketing artifact - adding personal and artistic value for an extremely complex and expensive object, even more desirable if is addressed to personal creativity. Not only a tool, but also an object for fun, creativity, skills; a specialized, complex, mechanical artifact with which one interact and becomes an extension of personality, opening a new fantasy world for everyone. As the Hammond Typewriter Company stated in its 1900 book. Art in Typewriting, it was 'the modern machine, with modern methods, for modern men'. Poet and novelist Robert Graves said that a typewriter 'of which you have grown fond seems to reciprocate your feelings, and even encourage the flow of thought. Though at first a lifeless assemblage of parts, it eventually comes alive (Tullett, 2014: 12-13). 
This article is mainly about the potential of technologies contemporary, modern, mainstream and even outdated - as vectors of learning in contemporary artistic education, in the effort of finding solutions for the ever growing gap between artistic tradition, students and contemporary artistic realities of the $21^{\text {th }}$ century and its labor market.

During art classes and workshops, children, students and adults alike are mesmerized by typewriters, especially by functional ones. They instantly interact with them, even if they don't understand how it works. They are also amused by the presentation of typewriter as the ancestor of smartphone, text message, and digital printer - the only similar object, in terms of formal analogy, is for them the computer keyboard. In fact, with the typewriter, not the artistic product is fascinating, but the process itself all the articulations and the strictly mechanical interactions. The process of typing is now widely artistic, not only the artifact, as printed/typed sheet of paper. They are beautiful things, a connection to a bygone era. Sometimes, especially on the office machines, there's a residue of make-up embeded in the keys and the rollers, and you also get marks where the typists'nails have struck the keys. All of these things, they reveal a historical event, time, a moment, traces. It raises more questions than gives answers to. That's the mysterious story - you make the rest up... It's whatever you want it to be. Using a manual typewriter has unlocked a bidden part of me. It's given me permission to be okay with, even celebrate, and appreciate, mistakes. Depending on what I'm doing, I usually either start again, or make the mistake into part of the work. I quite like [it] ... when that 'mistake moment' makes you change your mind about your original idea, often to go on to produce something much better, and more creative. The sense of bistory imbued in a typewriter that you own is a marvellous feeling. So many stories. Now, of course, it is quite the opposite. A dead technology. An antique. A rather amusing piece of our cultural history that we can look back an laugh at ourselves for having found so sophisticated and clever. It is now almost impossible to imagine a time when the typewriter was vital to our commercial and artistic life. Yet, despite the word processor, the PC, the iMAC, iPhone, iPad and the myriad other tablets, phablets and devices designed to allow us to compose and disseminate our thoughts, it still retains an importance. It is still a signifier of the writer, the critic, the intellectual. In itself, as an object in our modern world, it is a potent visual shorthand. It signifies the move into the Modern Era, towards the mechanisation of our lives (for good or ill) and is a symbol of progress that leads directly to the path of the PC. To have a typewriter as an ornament indicates a certain kind of person; to have a typewriter as a functioning object indicates yet another. A newspaper recently ilustrated an article about whether the ability to post immediate comments online has meant the end of the critic with a falling figure - a Mad Men-style silhouette - with bis typewriter by his side. Author Will Self has spoken about the attitude that the typewriter brings to creativity: 'The computer user does their thinking on the screen, and 
the non-computer user is compelled, because be or she has to retype a whole text, to do a lot more thinking in the head.' The god of the computer is a forgiving one; the god of the typewriter is not (Tullett, 2014: 13-15).

The art of the typewriter refers not only to the process and the printed/typed artefact, although the latter is the backbone of this artistic and technological typology, through the infinite variants of schemes and compositional structures that use letters or graphic signs. The artifact itself, the typewriter, is a vector for artistic education in the area of contemporary sculptural object. Beyond readymade status, the typewriter can be systematically deconstructed, teardown in the amazing complexity of all its mechanical parts, in the style of Todd McLellan, in his famous interactive art project, Things Come Apart (McLellan, 2013). The next step to this deconstruction process is obviously to reconstruct it into the compositional structure of a contemporary sculptural object, depending on the student's imagination. It is an exercise which, depending on the creative and technological appetite of the students, I proposed in my teaching activity to be studied and developed to almost every generation, with extremely interesting results.

Artifacts produced by this form of art and artistic research are mainly of three types: graphic art, three-dimensional objects/sculpture and process art, performance, installation art. The graphic art of the typewriter is found on a multitude of media, colors and formats, starting from the classic A4 sheet; usually the printed letter acquires the status of the visual module, sort of pixel, the basic component of a machine drawing, determined by the limitations and the creative challenges of thetypewriter, which evolves as technological support of a contemporary art form. The sculpture, threedimensional object is usually the typewriter itself, functional or not, deconstructed and reconstructed by adding readumade elements or other media facts - colors, textures, shapes, etc. The resulting sculptural object can be just the icon of a typewriter, such as Claes Oldenburg's Soft Typewriter, Ghost Version (ArtStack, n.d.) made of vinyl. The third stage of artistic manifestation of the typewriter technology as artefactual medium refers to the aesthetic qualities of the artistic process, performance and installation; letter printing, drawing by letters, full-analogue mechanical action becomes art in itself, recorded and documented visually and audibly - keyboard sounds can be structured and processed in musical schemes; also, technological context of the typewriter can be changed, altered, interpreted: is the case study of famous typewriter converted into gas burner, the work Homage of Leopoldo Maler (Gettyimages, n.d.) in The Hess Collection Winery, Napa Vineyard, inspired by his uncle, an Argentinian writer. 


\section{The Voodoo Artifacts}

This topic is included in the article due to the famous Arbogast collection of voodoo artefacts (ArtStack, n.d.) mainly because it is quite different from what one would expect from a private collection of this kind, even institutionalized as a museum. The Arbogast collection is vivid and alive, meaning that its artefacts are modern and contemporary made, gathered over three decades, from the areas where voodoo religion is still practiced - in other words, are liturgical artifacts of the present. The scientific outfit and the authenticity of the collection are absolutely impeccable and the presentation catalog could be already considered a milestone for the interdisciplinary area defined by anthropology, art, and multiculturalism.

Apparently, voodoo artifacts are not technological objects, although most of them contain contemporary readymade items - metal objects, glass bottles, strings, textile fragments, etc. But the process of making, overlapping or even identified with the religious ritual, becomes and can be interpreted as a highly spiritualized technology of transposition - a kind of religious, anthropological, psychological and spiritual technology. In this way, the obvious formal analogies with modern and contemporary sculpture are fully justified: the works/sculptures, installations and performance art of Joseph Beuys, art brut and outsider art.

One need only think of the works of Joseph Beuys and his use of fat, and the link he created between art and shamanism, or Annette Messager, who incessantly knits, pierces and swaddles personal objects for her installations or, more recently, Myriam Mibindou with her "sculpted flesh" series, Julien Salaud, who pierces and wraps taxidermied animals, or Alice Anderson with her sculptures made of twisted hair or buildings invaded by miles of hair, reflecting trauma, grief, and oblivion. This idea of dressing a wound can likewise be found in the work of Judith Scott, a mute artist with Down Syndrome, exhibited at the Musée de l'Art Brut in Lausanne, whose works are surprisingly close to some of the objects that appear in this book. Finally, by studying the works of these contemporary artists who incorporate organic materials, work on bodyprints, and repeat gestures like threading, nailing and stuffing, we understand the importance of gesture in the creative process, which is sometimes more important than the object it produces.

The work made ultimately counts less than 'making the work' (Fréchuret \& Davila, 1999: 31). It is therefore not surprising that the voodoo object fascinates many contemporary artists, as voodoo is action and the voodoo object is a "performing", even therapeutic object. "Making work" makes it possible to both welcome misfortune and ward it off. Making work pinpoints the root of our inner chaos and then expulses it, by 
transferring it to the object in order to restore balance. The strength of this chaos is contained by the net of words that made it exist. The crust thickens, the padlock opens, as the object awaits yet another narrative to continue its transformation (Muller, 2013: 158).

One of the usual readymade objects currently introduced into the voodoo practice of artifacts-ritual is the padlock. Obviously, the artifact is profoundly symbolic in any culture and civilization and has long penetrated into the collective imagination. However, the practice of voodoo artifacts is an example of creativity, mainly as a sculptural artistic process, as far as this article is concerned. The metal padlock is the modern-day equivalent of a wooden stake planted in the head or chest of a magical statuette. Symbolically, its function is to seal the incantatory words of its mission within the object - literally, the hopes one has placed in it. The number of padlocks on a given object can be a mark either of its function, or of its success. Some objects with only one padlock serve a single person. Other objects are adorned with a rainbow of multicolored padlocks. These bo/djoca, whose efficacy has been proven, are sought by many consultants. Thus, at the end of a ceremony, the priest closes the lock, removing the key and putting it in a place known only to him or her. When the object is made to seriously harm another person by putting a spell on him, the key is thrown into the river, making it impossible to lift the curse. Typically, however, keys stay in their locks and are only turned once, so that the priest can easily free the words inside at the consultant's demand. Usually reserved for spells (like, for example, on the duck head meant to render a plaintiff mute when be goes to court), the padlock's prescription depends on the $\mathrm{Fa}$ divined during a geomantic consultation session. The priest buys the padlocks at the nearest market - the same kind used to lock suitcases. However, in the ritual context, they take on new meaning, becoming part of a language in a society that, for a long time, declined to use alphabetic writing. This belief in the padlock that helps secure wishes is universal, evoking the same rite that couples in love borrow when they pledge their fidelity by attaching a lock to chain-link barriers on the Pont des Arts in Paris (Muller, 2013: 234).

Todd McLlellan's book, THINGS COME APART - A Teardown manual for modern living has a huge footprint in the online environment. It can be said that it launched a fashion, including in the artistic environment, with direct reference to the process of deconstruction of common, mass produced objects. In this case, the systematic deconstruction of an object is a cognitive and analytical process, followed by a rather artistic and aesthetic interpretation of individual and subjective situations: arranging the component parts in a creative way and in a certain order, followed by the documentation and the photographic interpretation of the ensemble obtained in the elaborated studio process. In other words, it can be interpreted as a sculptural process, performance and much more. When 
taking objects apart, I organize the pieces in separate containers in the sequence in which they are removed. So, for example, when dismantling a phone, all the headset pieces stay together in one tray and the ringer pieces stay together in another. These trays are then kept in order, ready for layout. I am very careful to make sure yhat none of the pieces is lost in the process. The thrilling part about disassembling an object myself, even before the photography, is the oportunity tu understand the manufacturer's challenge. I gain a basic understanding of how the item works and, in turn, a greater respect for it. When everything is finally separated, I begin arranging the elements on a neutral backround. Unless I am doing a 'drop' - a description of which follows - each object I disassemble is laid out in the same fashion. First, I position the main component, usually the exterior shell. After that, placing the parts in a beautiful shape is a bit of a purzle, and I repeatedly rework the layout to make each piece fit in the space. If it takes one-and-a-balf days to take an object apart, it takes just as long, if not longer, to lay it all out and achieve the right composition. Even the smallest objects take three days or more. What comes in a tiny case may fill a surface 3 metres square, (32 square feet) so anticipating the size of the spread in advance is very difficult. This is especially true with the latest technology. As manufactured objects have evolved, they have become far more complex. Components are becoming more numerous, even as they decrease in size. The full size of the disassembly, with every single component laid out, can be buge in relation to the original object. It is as if the true scale of the object is revealed only when it is taken apart (McLellan, 2013: 10). In our opinion, McLellan's system is a highly creative and well-founded case study suitable for any contemporary course in composition, and not just for contemporary sculpture. It has everything it takes for an educational, creative and artistic training process: the choice of the object identifies the area of interest or the curiosity of the student; deconstruction requires discipline or, on the contrary, destruction or direct fragmentation; the arrangement of fragments in various compositional schemes also indicates the aesthetic preferences or the area of individual interest, the personal research route; the technique of photographic documentation is also the choice of the student; a stage of creative reconstruction, the interpretation of the object, or even a collage of fragments belonging to several artifacts can be introduced, perhaps even a common work by the team. The objects in this book were photographed in two ways. In the first - mentioned above - I stayed faithful to the assembly and tried to lay out the pieces in the order in which they were revealed. This creates an image that is quite precise and formal. almost like a family portrait. The camera is set up directly above, shooting downwards. The only lightning is one flash head, which is bounced off a large reflector above the camera. This bounced lightning leads to a soft quality while providing some depth to the scene. I think of the second method as setting the parts free. The pieces are placed on a platform near the ceiling, then dropped. They are arranged so that, as they fall 
through the camera frame, their appearance conforms closely to what I had in mind. Using the newest and fastest strobe-lightning technology, I am able to freeze the pieces mid-frame. Originally I tried to capture all of the falling pieces in a single shot (one of the phone images was done in that way), but since then I have had more succes dropping the pieces in groups and then layering the resulting images in post-production, usually in foreground, mid and backround sections. At first I tried light triggers to set off the camera and flash, but now I get the best results by watching the pieces fall and pressing the shutter at the precise moment that I see something exciting happen. (...) Things Come Apart has been an exercise in discovery, and I'm not sure where it will end or what I will explore next (Mc Lellan, 2013: 10).

\section{Case study. Götz Diergarten - Documentary Style Object}

Götz Diergarten photographs architectural objects - facades, beach pavilions, details of subway stations - but in a documentary style photography defined by the originality of vision and perception. The references of his art are recognizable due to his studies with Bernd Becher ("Who Are Hilla", n.d.) in Düsseldorf. Typical architectural structures become sculptural objects in his photographs, defined by the frontal and hieratic, almost totemic vision, the tight composition and the trimming of the documented image, with a strict reference to the object under investigation. The same reference of the Düsseldorf $S$ chool is also found in the variety of investigated typologies, determining the apparent taxonomic classification of its projects. In one of them, Back to the Roots, there is also a subway station in Bucharest ("Alles so Schön", 2011).

In our opinion, the case study on Götz Diergarten is completed in the article's topics by another German photographer, Ulrich Hensel ("Ulrich Hensel", n.d.); its area of interest and investigation relates also to architectural structures and objects, but on the construction site level concrete volumes, textures and colors of building materials that are perceived, documented and interpreted as sculptural objects, painting panels and creative structures. Through his photographs, Götr Diergarten encourages us to look at the familiar things in our surroundings with greater sensitivity. In his typological series he investigates ordinary architecture: German façades, Belgian beach buts, British beach buildings, and European subways. The ostensible banality of plaster and fake brick, windows, garage doors, and simple architecture is transformed into a typology of everyday culture through the photographic series. His works are characterized by the clear, documentary style of his teacher Bernd Becher. House façades, beach huts, and subways are photographed according to strict compositional criteria - frontal view, diffuse light, and close cropping, the only variant is the type. What makes Diergarten's work so original is 
above all the conceptual link between typology and color (Götz Diergarten, Carsten Ahrens, \& Weserburg Museum für Moderne Kunst, 2010: 7).

\section{Case study. Traditional technologies and experimental status in Contemporary Visual Arts. Postmodern synthesis, cultural context and contemporary perception}

We have at least two perspectives on technology in the context of contemporary visual arts - first, modern transposition technologies, taken directly from the mainstream or even from the research and development area, and second, the traditional industrial technologies, now completely overcome but extensively documented during the $19^{\text {th }}$ and $20^{\text {th }}$ centuries. All of these technologies and theirs complete documentation (blueprints, patents, photographs, films, artifacts, etc.) are already cataloged and studied within dedicated archives and specialized collections. Thus they form a permanent cultural reference fund for any contemporary artistic manifestation, especially in an interdisciplinary area. In a constant phenomenon, especially in the last two decades, all major publishing houses edited books that are the result of cultural and artistic trends, from mainstream or underground; the references come from miscellaneous domains, but all relate to contemporary visual arts areas that values from artistic, aesthetic and anthropological point of view a lot of technological artifacts - movie cameras and projectors from the beginning of the $20^{\text {th }}$ century, steam engines, lighthouses - blueprints and building schemes, optics, etc. - flying machines, iconic design artefacts and countless others. The final conclusion would be that many of these editions - some highly specialized, others for the general cultural audience - can be starting points for courses and workshops in the field of contemporary visual arts, as incipient motivations and illustrative models for interdisciplinary approaches to artistic research area: contemporary art courses and especially master classes.

This is the case with the famous collection of movie cameras owned by a famous institution: La Cinémathèque française. Pour reproduire le mouvement de la vie et dépasser la peinture, la sculpture et la photographie, immobiles par nature, il a fallu le concours de l'optique, de la mécanique, de la chimie, quelques centaines de'années et la passion, le génie de quelques hommes. Et le cinématographe est né. (...) L'évolution de cette petite caméra à manivelle a été d'une rapidité vertigineuse, tout comme l'a été l'adhésion du public mondial, fasciné, boulversé par la vision de ces images animée. Ce succès a été accompagné, souvent précédé, par une multitude de créations, d'inventions, de trouvaille techniques et de machines pour perfectionner les images en qualité et en 
originalité. De vastes laboratoires chimiques, des usines, des studios ont été édifiés, avec des ingénieurs, pour répondre à ces besoins de nouveauté et d'excellence. La caméra étant au centre de la créativité, son perfectionnement n'a jamais cessé. Des systémes ont été créés pour lui permettre de se déplacer sur terre, dans les airs, sous la mer, au rythme désiré par l'auteur des images. Des mécanismes ont été imaginés pour faire accélérer les mouvements ou les faire ralentir, ce qui permet de voir tout autrement (Mannoni, 2016: 2). Movie cameras, but especially those from the early $20^{\text {th }}$ century, are perceived today as seductive objects, artifacts producing images and emotions. Always being the symbol of the cutting edge technology of the moment, somewhat similar in terms of mechanical complexity totypewriters, but much more effective in capturing realities and visual language. They are also an essential stage, alongside the typewriters and analog cameras, in the democratization of visual language and communication in general. The evolution of these artifacts is steep and fully integrated anthropologically: printing, typewriting, digital printer, internet, facebook - for the written word. Drawing, painting, analog and digital photography, analog film, cinema, video and digital camera, smartphone. Interestingly, the creative niches - the $6 \times 6$ film, the Polaroid, the $8 \mathrm{~mm}$. film, the Lomography, and the related digital variants smartphone applications, have survived. The Internet - world wide web unified the both media - the written word, the text and the image, through the socialization platforms, guaranteeing the participatory approach, democratic access, and freedom of expression $-\mathrm{m}$ obviously with the inherent risks and nuisances - but the price deserves to be ever paid.

All of the artifacts and systems mentioned above represents a contemporary, deeply interdisciplinary and multicultural platform for Visual Arts. The adaptability and extreme modulation of the elements of this platform allow and favors any type of creative experiment - developing concepts, structuring teaching and learning processes, enhancing creativity and testing results.

The specialization within an artistic transposition system (photography/digital image of Ken Boyd ${ }^{1}$ ) and the extended investigation of a traditional technological field - the locomotive and especially the steam locomotive - lead to stunning results and exceptional aesthetic valorizations of a traditional technology (yet an area well defined in collective imagination - an anthropological constant, we can say, reffering to the imagery of the steam engine). Every detail of Ken Boyd's locomotives photographs, from bolts and

\footnotetext{
${ }^{1}$ Ken Boyd is a fine-art and experimental photographer, he works on fine-art printing, digital imaging and processing, lightning and infrared techniques, large format equipment. His work is published in many photography magazines.
} 
conduits to sheet metal and windows, is painstakingly evaluated and then digitally edited to enhance luminance, contrast, tonality, and color. The results are images bristling with details not visible in conventional images (Boyd, 2014).

A very good example of postmodern cultural vision over an outdated technology is the book resulting from the collaboration between the prestigious Thames \& Hudson publishing house and The National Archives of London; a rather artistic volume, based on the archive images of the symbol from the global commerce system that built the modern world a miscellany of lighthouses buildings. Copiously illustrated with engraved blueprints, optical construction schemes of lights and lenses, and all the technology that use to be the high-tech of its time, the book captures anyone with the technological complexity of an architectural structure that has long been a narrative and symbolic landmark in collective imagination, as well as in any $19^{\text {th }}$ and $20^{\text {th }}$ century artistic productions. On the one hand, lighthouses had become an integrated practical element in a mature functioning system of global maritime navigation. On the other, they were developing a retro charm, as an established part of the iconography of seaside holidays featured on postcards and railway posters, or welcome landmarks for healtby cliff walkers. Long before the worldwide system of lights entered into its late 20th-century decline, lighthouses had become relics of the past rather than symbols of the future, proud memorials of distant feats of engineering, largely forgotten acts of personal heroism, and a lost way of life (Grant, 2018: 35).

The helicopter Bell 47Dl ("Bell 47Dl Helicopter", n.d.) is a sculpture. And we do not call it, but the Museum. Arthur Drexler, long-serving curator of the design and architecture collections at MOMA, refused to collect more than a bandful of mechanical appliances during his tenure. He claimed that 'too often their design is determined by commercial factors, irrelevant, or even harmful to aesthetic quality'. But Drexler did aquire the Bell $47 \mathrm{Dl}$ helicopter which still hangs in the museum, having moved from one building into another. The bright-green machine, with its space-frame tail structure and its Plexiglass bubble of a cabin, is an object that Terry Riley, the former curator of architecture and design at MOMA, once referred to as 'our winged victory'. He made the remark during a discussion on the power of placement. The Lowve's Winged Victory is at the top of a staircase, a message about its importance clear enough to the vast majority of visitors who have never heard of Samothrace. MOMA's helicopter floats above a staircase too, though it dangles from a web of cables. (...) Even when Drexler aquired it for the museum, in 1983, the production line for it at Bell had already been dismantled for a decade. What now singles out the 47Dl above all other helicopters is that it was the first helicopter in the world to have been hung in a museum of modern art. And that is why it is where it is. It embodies the museum and its history as much as anything intrinsic it has to say about helicopters. It's both beautiful and useless (Sudjic, 2014: 155). However, the story is somewhat more complex about this artifact - 
although the above quote is perfect for the main topic of our article, it must be said that the helicopter is more than a revolutionary design and technology of its age. The artefact - in fact, its military version served in the Korean and Vietnam Wars, becoming a symbolic image through the news movies, documentaries and motion pictures - not to mention the wellknown MASH - TV series, where the small medical helicopter appears on the generic with its now famous plexiglass bubble cockpit and tail made from aluminum tubes.

$$
\text { In the case of designer Ron Arad }
$$

(http://www.ronarad.co.uk/home/) is proved the ambivalence of relationship between technology and Contemporary Visual Arts - more precisely the sculptural object status through ready-made items. The artist launched his career with a now iconic chair design, the famous Rover Chair (Arad, 1981, 1986), made from industrial items recovered from the scrapyard. Decades later, a short series of this design was to be made, for which the recovered ready-made items were no longer available, so it needed to be industrially produced and fabricated. The conclusion is somehow amusing - ready-made elements now part of an iconic design based on ready-made concept had to be reproduced within industrial process - a perfect reverse action to the original, creative one. Ron Arad began as a designer using ready-made components to produce furniture, scavenging from scrapyards. His endless inventiveness has made bim as much an artist as a designer, giving bim the scope to return to the Rover Chair, his earliest work, and transform it. The limited - edition version produced in 2007 uses specially made industrial components to replicate what he could only salvage when he started out. Arad's work straddles the gap between art and design, usually not in the same piece but by pursuing parallel careers in mass production and oneoffs, such as the Well Tempered Chair (Sudjic, 2009: 187).

Extremely useful for contemporary artists are the DIY publications which had, however, reached a level of professionalisation not yet achieved until now, thanks in particular to digital documenting and editing technologies. The documentary and referential value of these books for Contemporary Visual Arts lies in taking over the techniques and technologies of transposition and fabrication, especially in the area of the contemporary sculptural object. A good editorial example are DIY handbooks on the fashion design accessories - bags, shoes, etc., with a level of documentation and detail that reminds somewhat of the famous L'Encyclopédie de Diderot et d'Alembert (n.d.) - itself a constant source of extended documentary for contemporary art, because it always works like a clip art book. The most practical handbook for accesories designers - The Fashionary Bag Design is a complete bandbook focusing on the practical needs of bag and accesories 
designers. It provides an insightful and inspirational foundation about bags and their key fundamentals to those in the fashion industry. The book showcases 3 major sections: 1. Bag Library - Bag Library featuring 300+ styles of bags ranging from the historical times to the most signature designs in the bag and small leather goods industry. 2. Bag Encyclopedia - Bag Encyclopedia focuses on the most essential and practical bag design information ranging from materials \& construction to brand position \& fairs. 3. Bag Templates for Tracing - The templates section included 60 styles of popular bags and small leather goods from clutch to luggage for tracing. All templates presented have been professionally modified for the best tracing experience (Mia \& Yip, 2016).

Any reform of the artistic education system is necessary in the sense of evolving and adapting to the contemporary realities of the labor market, to cultural trends, including subcultures of the underground, concidering that most of it will form tomorrow's mainstream. The main problem with the term of reform is that it has been degraded and looked suspiciously due to almost three decades of usually chaotic changes and slips that have disturbed the entire Romanian educational system. Another premise that partially justifies the present situation in the artistic educational system is the natural evolution from the Academy of Arts statute to the University of Arts situation, from academic protochronism to the standards of an university educational system in a European context. Due to this massive change in status it has been introduced a completely new working concept, the scientific research, partially assimilated under the phrase of artistic research. And all this process of changes, reforms, slips of all kinds and attempts to align with contemporary realities took place amid a dramatic drop in the number of students, the constant diminishing of their professional skills and the much better educational offer by art universities from the European space. The cleavage between institutional educational offer and the level of expectation for the students, formed by the realities of the labor market, is not at all new; the traditional, classical conditioning of the older teaching staff, a kind of well tempered modernity with protochronist references makes it difficult to interact and dialogue with the young generation of students already used with the contemporary phenomenology of pop art, described by Marvel characters, urban graffiti, underground movements, digital revolution, smartphone applications, 3D scanning and printing, social platforms, etc. Academic customs, the study of classical plasters and live model are outdated for them, with a very low level of interest. Interestingly, this type of crisis has already been covered by British art universities since the 1960s.

(...) processes of teaching and learning were undertaken in the face of fierce disputes about figuration, abstraction and, in due course, conceptual art; that there were artist-tutors who were prepared to throw over long-established ways of working and adopt 
new sets of artistic aims while remaining faithful to long-standing but usually untheorised and often unarticulated systems of teaching; that there were arguments about the very place of pedagogy in the art schools (Llewellyn \& Williamson, 2015: 10).

\section{Art education and public engagement}

Unlike other areas of university education, Visual Arts have a maximum public exposure, especially in the social media. Usually, Visual Arts are on the bottom of the list when financing is involved, due to traditional social bias, as if it were an elitist activity, highly specialized at the level of the end product - the artistic object: expensive, difficult to understand and digested, intended for a a long-term investment. Quite wrong actually - today the art object is already a consumer object with a rather permissive price tag, due in particular to modern transposition technologies, to diversity and accessibility of potentially artistic materials. About the public access and exposure of exhibitions, things are also changing, especially in the big cities area - visibility is maximized, but through the social media as Facebook, fed by all parts directly involved artists, visitors and specialized press. One was the enduring perception of art as an elite activity, a view that would make funding art education regressive, as the many would be paying for the few. The other was art education's transparency: the public could engage with art school output, for example, in the form of degree shows, much more easily than with maths degree these or exam scripts. The cost of this engagement was the disproportionate exposure of art schools to public criticism (Llewellyn \& Williamson, 2015: 45).

The vast majority of today's Art Universities have evolved from a traditional system of Art Academies and Art Schools. However, the University system provides and impose a set of clear quality standards, with specific activities that can not be circumvented in any way based on prior professional expertise and skills: research, in this case artistic research. The organizational culture of the University and research impose to the educational field of Visual Arts to adapt and evolve primarily in intellectual and research areas, based on social and cultural realities and contemporary paradigms. There are already successful European examples in the field of Visual Arts Universities, but also the large mass of the universities that share the same problems: underfinancing, difficulty in adapt and maintaining university standards, protochronism of teaching and learning processes. (...) the new pedagogic practices developed at St Martin's in the mid 1960s started to promote a fresh but still enduring image for the artist as a species of public intellectual rather than as a studio-based maker of objects (Llewellyn \& Williamson, 2015: 23). 


\section{Conclusions}

Conclusions from this analysis are not necessarily positive or optimistic. The process of reforming, adapting and evolving the Art Education towards the university organizational culture has already gone for over two decades, at least in the European space. In fact, the essential issue does not imply the reduction or limitation of practical skills teaching and learning, but their adaptation to contemporary realities (traditional and digital technologies, critical thinking, artistic research) through the methods and case studies described above in this article. (...) the seemingly inexorable shift in art education away from manual skills towards an understanding of theory, which is expressed verbally even if it is applied visually. In addition, there has been an unrelenting process over the last twenty or so years, to bring art education within mainstream higher education (Llewellyn \& Williamson, 2015: 153-154).

At this moment, the outcome of mixing the practice of Art Education with the university and research culture is difficult to anticipate, but the solution can only come from within. The institutionalization of artistic research in teaching and learning processes is essential, supported by the practice of critical thinking, not only for students, but for teaching staff. The digitization of teaching and learning, including in studio courses, is quite easy to achieve, at least as on-line references to documentary resources of the Internet, through social media instantly accessed from common devices laptop, smartphone, tablet. Innovating traditional transposition technologies by adding creative technologies outdated in post-industrial era (case studies above). Large scale introduction of digital transposition technologies: - 3D scanning and printing, CNC, 3D modeling software for tablet and laptop use. Involvement of students in artistic research projects and especially in participatory art projects, a particularly useful trend for contemporary Visual Arts for social involvement and valorisation of intellectual and practical skills for art students. pag. 24 There are still debates in art schools about the balance in the curriculum between instruction in manual skill or process and instruction in communication or theory, and the eventual impact of university and research cultures on art school teaching remains unclear (Llewellyn \& Williamson, 2015: 24).

\section{References}

Alles so schön bunt hier [Everything's so colorful here]. 2011, December 03. Retrieved from https://www.zeit.de/reisen/2011-11/fs-goetz-diergartenback-roots

Arad, R. (1981). Rover chair. Retrieved from https://www.moma.org/ collection/ works /126043 
Arad, R. (1986). Well tempered chair. Retrieved from http://www.ronarad.co.uk/studio-pieces/well-tempered-chair/

ArtStack. (n.d.). Home. Retrieved from https://theartstack.com/artist/claesoldenburg/soft-version-ghost-typewriter

Muller, B., \& Snoep, J. N. (2013). Voudou/Vodoo. Strasbourg, France: Loco.

Bell 47Dl helicopter . (n.d.). Retrieved from https://en.wikipedia.org/wiki/Bell_47

Boyd, K. (2014). The art of the locomotive. Minneapolis, USA: Voyageur Press.

Fréchuret, M., \& Davila, T. (1999). L'art medicine, Musée Picasso, Antibes. Paris, France: Éd. de la Réunion des musées nationaux.

Gettyimages. (n.d.). Exploring Napa Valley's hidden wineries. Retrieved from https://www.gettyimages.com/detail/news-photo/burning-underwoodtypewriter-entitled-homage-by-artist-news-photo/146122990

Götz Diergarten, Carsten Ahrens, \& Weserburg Museum für Moderne Kunst. (2010). Götz Diergarten - Photographs. Osfildern, Germany: Hatje Cantz Verlag.

Grant, R. G. (2018). Sentinels of the sea - A miscellany of lighthouses past. London, UK: Thames \& Hudson.

Klein, J. (2010). What is artistic research? Retrieved from https: //www.researchcatalogue.net/view/15292/15293

L'Encyclopédie de Diderot et d'Alembert [The encyclopedia of Diderot and Alembert]. (n.d.). Retrieved from https://archive.org/details/gri_33125006581629/page/n551

Llewellyn, N., \& Williamson, B. (2015). The London art schools: Reforming the art world, 1960 to now. Mustang, USA: Tate Publishing.

Mannoni, L. (2016). La machine cinema - De méliès à la 3D [The cinema machine From melie to 3D]. Paris, France: Lienart and La Cinémathèque française.

McAllister, J. (2004). Seven claims. Balkema/Slager.

McLellan, T. (2013). Things come apart - A teardown manual for modern living. London, UK: Thames \& Hudson.

Mia, M. M., \& Yip, P. (2016). Bag design - A handbook for accessories designers. Fashionary International Ltd.

Organisation for Economic Co-operation and Development (OECD). (2008). Glossary of Statistical Terms. Retrieved from https://stats.oecd.org/glossary/

Society for Artistic research (SAR). (n.d.). About. Retrieved from http://www.societyforartisticresearch.org/jar/

Sudjic, D. (2009). The language of things - Understanding the world of desirable objects. New York, USA: W. W. Norton \& Company. 
Tullett, B. (2014). Typewriter art: A modern anthology. London, UK: Laurence King.

Ulrich Henselhttp://photography-now.com/artist/ulrich-hensel. (n.d.). Retrieved from https://en.wikipedia.org/wiki/Ulrich_Henselhttp://photographynow.com/artist/ulrich-hensel

Who are Hilla and Berndt Becher. (n.d.). Retrieved from

https://www.tate.org.uk/art/artists/bernd-becher-and-hilla-becher-

718/who-are-bechers 